\title{
Analisa Potensi Bahaya dan Upaya Pengendalian Kecelakaan Kerja Pada Proses Penambangan Batu Adesit di PT. Dempo Bangun Mitra
}

\author{
Muhammad Ihsan Hamdy ${ }^{1}$, Lailatul Syifa Tanjung ${ }^{2}$ \\ ${ }^{1,2}$ Jurusan Teknik Industri, Fakultas Sains dan Teknologi, UIN Sultan Syarif Kasim Riau \\ Jl. HR. Subrantas No. 155, Simpang Baru, Pekanbaru, Kode Pos 28293 \\ E-mail: ihsanhamdy@ymail.com
}

\begin{abstract}
Abstrak
PT. Dempo Bangun Mitra merupakan sebuah perusahaan pertambangan yang telah menerapkan program Keselamatan dan Kesehatan Kerja. Walaupun perusahaan telah menerapkan beberapa standar atau prosedur keselamatan kerja, dalam pelaksanaanya masih terdapat beberapa potensi bahaya yang dapat menimbulkan kasus kecelakaan kerja. Apabila potensi bahaya yang timbul dapat diidentifikasi dan dikendalikan, maka angka kemunculan kecelakaan pun dapat menurun. Identifikasi dan pengendalian potensi bahaya dapat dilakukan dengan menggunakan metode Hazard And Operability Study (HAZOP). Hasil obervasi menemukan 34 potensi bahaya (hazard) dan kemudian digolongkan menjadi 9 sumber hazard. Berdasarkan penilaian level risiko, terdapat 2 sumber hazard yang tergolong "Ekstrim", 5 sumber hazard yang tergolong "Risiko Tinggi", 2 sumber hazard yang tergolong "Risiko Sedang", dan 1 sumber hazard yang tergolong "Risiko Rendah". Penelitian ini menghasilkan rekomendasi perbaikan berupa pembuatan Standard Operating Procedure (SOP), jadwal pelatihan penggunaan Alat Pelindung Diri (APD), worksheet penggunaan APD, lembar kontrol penggunaan APD, pemberian rambu-rambu kondisi lalu lintas tambang, dan checklist lalulintas tambang.
\end{abstract}

Kata kunci: $H A Z O P$, Kecelakaan Kerja, K3, Risk Analysis

\section{Latar Belakang}

Perkembangan teknologi saat ini sangat berpengaruh terhadap perkembangan kegiatan pertambangan. Perkembangan kegiatan pertambangan pada era globalisasi saat ini dirasakan sangat perlu untuk mengikuti tuntutan jaman yang menginginkan perubahan di segala aspek. Berbagai kegiatan pertambangan belombalomba memenuhi tuntutan tersebut. Hal itu tak hanya terjadi pada kegiatan pertambangan di Indonesia melainkan industri di seluruh dunia. Perkembangan kegiatan pertambangan di Indonesia kini dalam tahap pertumbuhan yang meningkat. Agar tuntutan tersebut terpenuhi maka diperlukan kondisi operasional kegiatan pertambangan yang handal, lancar, efisien, dan aman (Yovita, 2009).

Sebagai upaya memperoleh kondisi operasional yang aman memerlukan penerapan sistem kesehatan dan keselamatan kerja (K3) serta pengelolaan penerapan sistem menejemen kesehatan dan keselamatan kerja (SMK3). Menurut Depnakertrans RI, Keselamatan dan Kesehatan Kerja adalah segala daya upaya dan pemikiran yang dilakukan dalam rangka mencegah, mengurangi, dan menanggulangi terjadinya kecelakaan dan dampaknya melalui langkah-langkah identifikasi, analisa dan pengendalian bahaya dengan menerapkan sistem pengendalian bahaya secara tepat dan melaksanakan perundang-undangan tentang keselamatan dan kesehatan kerja.

Sistem Manajemen Keselamatan Kerja (SMK3) menurut Kepmenaker 05 tahun 1996 adalah bagian dari sistem manajemen secara keseluruhan yang meliputi struktur organisasi, perencanaan, tanggung jawab, pelaksanaan, prosedur, proses, dan sumber daya yang dibutuhkan bagi pengembangan, penerapan, pencapaian, pengkajian, dan pemeliharaan kebijakan keselamatan dan kesehatan kerja dalam pengendalian risiko yang berkaitan dengan kegiatan kerja guna terciptanya tempat kerja yang aman, efisien, dan produktif. Sehingga dengan adanya sistem menejemen kesehatan dan keselamatan kerja (SMK3) maka proses penerapan kesehatan dan keselamatan kerja (K3) dalam bidang penambangan dapat berjalan secara aman, efektif dan efisien.

PT. Dempo Bangun Mitra merupakan salah satu perusahaan yang bergerak di bidang pertambangan serta pengolahan batu andesit. Batu andesit merupakan jenis batu alam yang biasanya digunakan untuk pembuatan dasar jalan raya atau bangunan-bangunan megalitik seperti 
candi dan piramida. Perusahaan ini melakukan beberapa tahapan untuk menghasilkan berbagai macam ukuran batu andesit. Adapun tahapan dalam menghasilkan batu andesit adalah mulai dari tahap identifikasi lokasi penambangan, proses peledakan untuk mendapatkan batu andesit yang berukuran besar, serta proses pengolahan batu dengan menggunakan mesin cruser stone untuk menghasilkan beberapa ukuran batu yang diinginkan.

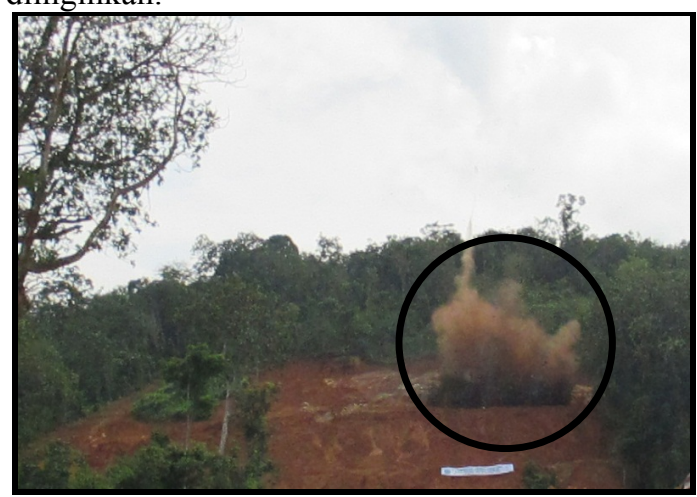

Gambar 1. Peledakan

Hasil studi lapangan menunjukkan bahwa lingkungan kerja PT. Dempo Bangun Mitra saat ini berpotensi mengganggu kesehatan manusia, misalnya pada tahap awal dalam menghasilkan batu andesit yaitu tahap peledakan. Tahap peledakan ini diawali dengan proses awal yaitu perusahaan melakukan identifikasi lokasi peledakan, setelah didapatkan lokasi mana yang terdapat batu andesit maka tahap selanjutnya adalah melakukan proses peledakan (gambar 1) sehingga didapatkan batu andesit yang berukuran besar. Potensi bahaya yang dapat terjadi pada tahap ini adalah karyawan akan terkena serpihan batu andesit yang tebang akibat proses peledakan. Selain itu apabila proses perhitungan peledakan tidak sesuai atau kesalahan dalam prediksi area peledakan maka akan dapat menyebabkan kematian serta kerusakan lingkungan.

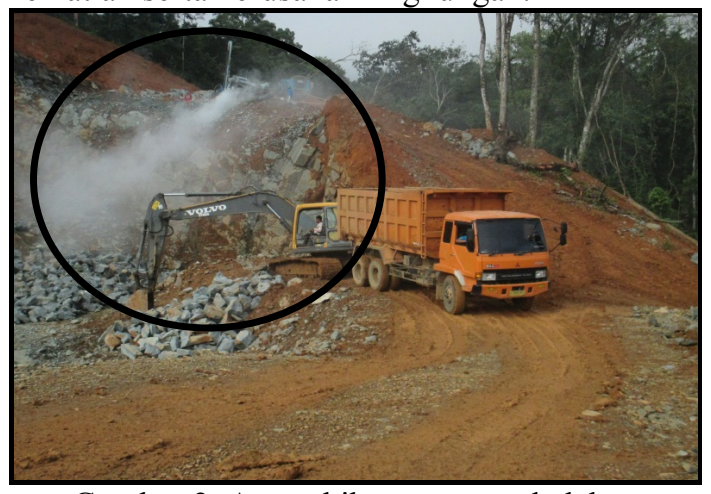

Gambar 2. Asap akibat proses peledakan

Pada gambar diatas (gambar 2) terlihat bahwa terdapat banyak asap di sekitar penambangan. Asap tersebut merupakan asap yang ditimbulkan akibat dari proses peledakan. Apabila asap tersebut dihirup secara langsung dan terus menerus maka akan mengakibatkan gangguan pernafasan bagi para karyawan di sekitar penambangan. Hal itu juga merupakan salah satu potensi bahaya yang dapat terjadi pada proses penambangan serta pengolahan batu andesit.

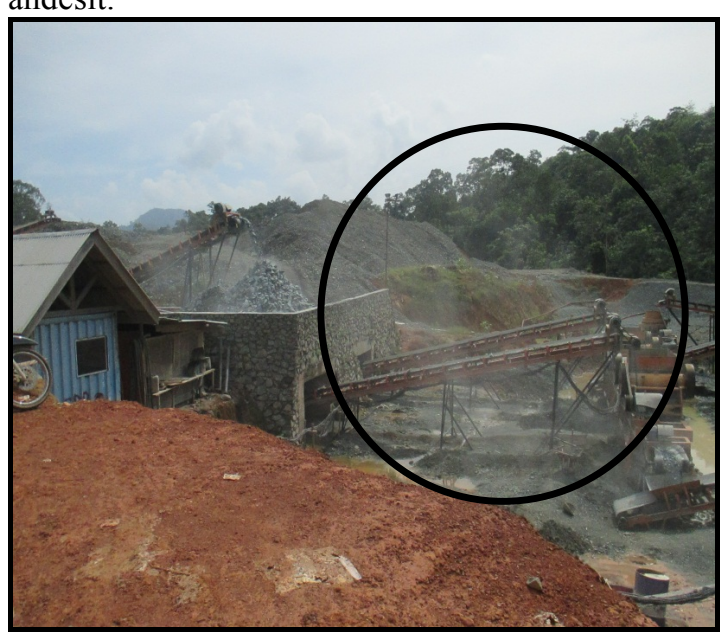

Gambar 3. Debu pada proses pengolahan batu

Selain pada tahap peledakan, potensi bahaya juga dapat ditemukan pada proses pengolahan batu atau proses pemecahan batu menjadi beberapa ukuran menggunakan mesin cruser stone. Hal ini dapat dilihat pada gambar diatas (gambar 3). Pada gambar diatas terlihat debu yang berada di sekitar mesin cruser. Apabila debu tersebut dihirup secara langsung dan terus menerus maka akan mengakibatkan potensi bahaya kesehatan pada karyawan di sekitar seperti gangguan pernafasan serta sesak nafas.

Untuk mengurangi atau menghilangkan bahaya yang dapat menyebabkan kecelakaan di tempat kerja maka diperlukan suatu manajemen risiko kegiatannya meliputi identifikasi bahaya, analisis potensi bahaya, penilaian risiko, pengendalian risiko, serta pemantauan dan evaluasi. Dalam proses identifikasi dan melakukan analisis potensi bahaya maka dapat dilakukan dengan menggunakan metode Hazard and Operability Study (HAZOP). HAZOP adalah studi keselamatan yang sistematis, berdasarkan pendekatan sistemik ke arah penilaian keselamatan dan proses pengoperasian peralatan yang kompleks, atau proses produksi. Tujuannya untuk mengidentifikasi kemungkinan bahaya yang muncul dalam fasilitas pengelolaan di perusahaan yang dapat menghilangkan sumber utama kecelakaan, seperti rilis beracun, ledakan dan kebakaran. Secara sistematis HAZOP bekerja dengan mencari berbagai faktor penyebab (cause) 
yang memungkinkan timbulnya kecelakaan kerja dan menentukan konsekuensi yang merugikan sebagai akibat terjadinya penyimpangan serta memberikan rekomendasi atau tindakan yang dapat dilakukan untuk mengurangi dampak dari potensi risiko yang telah diidentifikasi. Metode HAZOP merupakan salah satu metode yang banyak digunakan untuk mengidentifikasi jenis potensi kecelakaan kerja yang ada pada perusahaan.

Terdapat beberapa hasil penelitian sebelumnya yang dilakukan dengan dengan menggunakan metode HAZOP yaitu penelitian yang dilakukan pada PT.EKAMAS FORTUNA. Perusahaan tersebut telah menerapkan program $\mathrm{K} 3$, tetapi dalam pelaksanaannya masih terdapat beberapa potensi bahaya yang dapat menimbulkan kasus keselakaan kerja. Maka dilakukan identifikasi serta pengendalian bahaya dengan menggunakan meggunakan metode HAZOP. Hasil observasi menemukan 43 potensi bahaya dan kemudian digolongkan menjadi 15 sumber bahaya dengan golongan masing-masing bahaya yaitu eksrim, resiko tinggi serta resiko rendah. Penelitian ini menghasilkan rekomendasi perbaikan berupa pembuatan Standard Operating Procedure (SOP), Jadwal pelatihan APD, serta lembar kontrol penggunaa APD (Pujiono, dkk, 2013).

Berdasarkan permasalahan yang telah disebutkan diatas, maka dalam penelitian ini akan dilakukan analisis kecelakaan kerja dengan menggunakan metode Hazard and Operability Study (HAZOP) sehingga permasalahan yang ada akan terselesaikan serta terciptanya lingkungan kerja yang lebih aman, efektif dan efisien.

\section{Metode Penelitian}

Agar penelitian yang dilakukan lebih terarah dan sistematis, maka perlu dibuat tahapantahapan dari penelitian itu sendiri. Adapun tahapan dalam penelitian ini dapat dilihat dari gambar 4 .

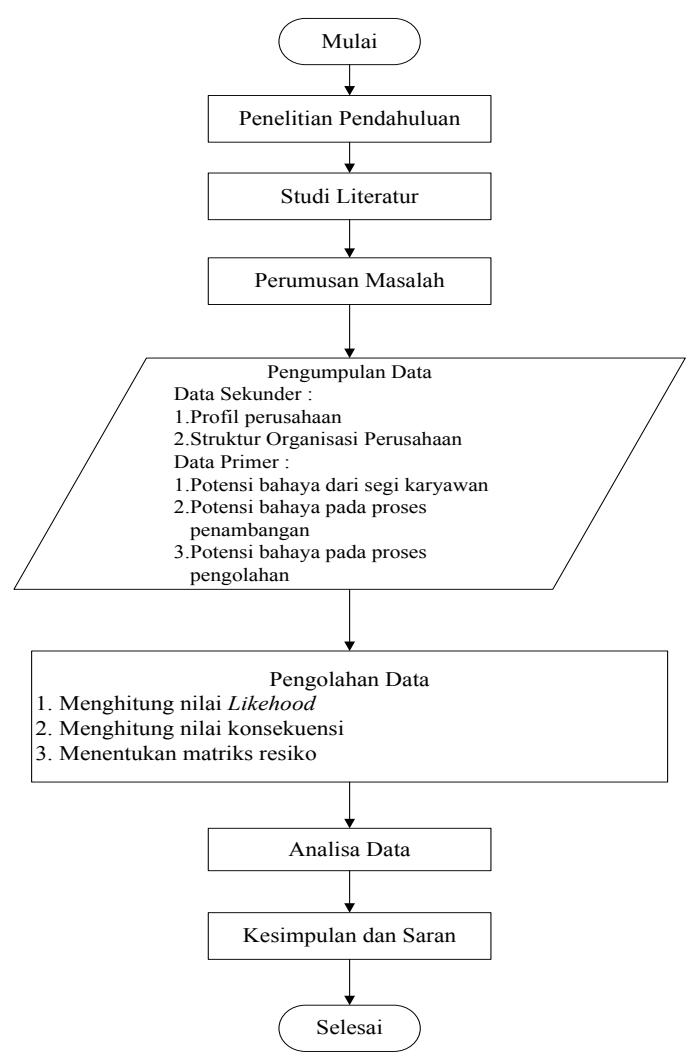

Gambar 4. Diagram Alir Penelitian

\section{Hasil dan Pembahasan}

\section{Pengolahan Data \\ Identifikasi Potensi Bahaya}

Sebelum mengidentifikasi potensi bahaya yang terjadi pada proses penambangan batu andesit di PT. Dempo Bangun Mitra, maka terlebih dahulu diuraikan alur atau langkahlangkah dalam proses produksi.

Proses penambangan batu andesit yang dilakukan di PT. Dempo Bangun Mitra adalah sebagai berikut :

1. Proses produksi penambangan batu andesit ini dimulai dengan land clearing yaitu membersihkan lahan penambangan dengan cara memotong pepohonan dan menyingkirkan segala sesuatu yang dapat menghambat aktivitas penambangan.

2. Setelah land clearing usaha selanjutnya adalah removing top soil yaitu mengambil dan memindahkan tanah pucuk yang dikumpulkan pada tempat penampungan top soil sementara yang diberi nama stockpile. Pengambilan top soil ini harus benar benar menjadi perhatian agar tidak tercampur dengan lapisan batuan atau tanah yang lain sehingga bisa dimanfaatkan lagi pada saat reklamasi dan revegetasi. 
3. Kegiatan selanjutnya adalah melakukan removing lapisan overburden $(O B)$ dengan pemboran dan peledakan.

4. Lapisan tanah $O B$ tersebut kemudian dimuat dan dibawa ke lokasi $O B$ disposal sampai terbentuk konsruksi yang direncanakan dan sampai pada lapisan batu andesit.

5. Setelah lapisan batu andesit ditemukan maka dilakukanlah digging and loading yaitu penggalian batu andesit dan dimuat kedalam truk Volvo untuk diangkut ke lokasi coal crushing plant (CCP) dan melalui proses produksi selanjutnya.

6. Batu andesit yang diangkut menggunakan Volvo tadi melewati weighbridge untuk ditimbang dengan kapasitas maksimal lima puluh ton.

7. Selanjutnya batu andesit ini ada yang dibawa ke tempat penampungan sementara dan serta dibawa ke crusher untuk dipecah sehingga mendapatkan size yang diinginkan.

8. Setelah penambangan selesai dilakukan tahapan yang selanjutnya yang harus dilakukan adalah reklamasi yang bertujuan untuk memulihkan kondisi kawasan hutan yang rusak sebagai akibat usaha pertambangan sehingga kawasan hutan yang dimaksud dapat berfungsi kembali sesuai dengan AMDAL.

\section{Potensi Bahaya dan Sumber Bahaya}

Berdasarkan hasil observasi lapangan terdapat beberapa potensi bahaya yang diakibatkan pada proses penambangan batu andesit. Potensi bahaya tersebut digolongkan atas 3 faktor yaitu faktor manusia atau pekerja, faktor bahaya pada proses penambangan serta faktor bahaya pada proses pengolahan batu andesit. Adapun temuan hazard atau potensi bahaya dapat dilihat pada tabel 1 .

Tabel 1. Potensi dan Sumber Bahaya di Tempat

Kerja PT. Dempo Bangun Mitra

\begin{tabular}{|l|l|l|c|}
\hline No & \multicolumn{1}{|c|}{$\begin{array}{c}\text { Potensi } \\
\text { Bahaya }\end{array}$} & \multicolumn{1}{|c|}{$\begin{array}{c}\text { Sumber } \\
\text { Bahaya }\end{array}$} & $\begin{array}{c}\text { Jumlah } \\
\text { Temuan }\end{array}$ \\
\hline 1 & Sikap Pekerja & & 8 \\
\hline 2 & Penambangan & Kebisingan & 4 \\
\cline { 3 - 4 } & & $\begin{array}{l}\text { Lalu lintas } \\
\text { tambang }\end{array}$ & 6 \\
\cline { 3 - 4 } & & $\begin{array}{l}\text { Serpihan } \\
\text { Material }\end{array}$ & 1 \\
\cline { 3 - 4 } & & Asap & 2 \\
\cline { 3 - 4 } & & $\begin{array}{l}\text { Area } \\
\text { penyimpanan } \\
\text { bahan peledak }\end{array}$ & 1 \\
\hline 3 & $\begin{array}{l}\text { Pengolahan } \\
\text { Batu Andesit }\end{array}$ & Debu & 5 \\
\cline { 3 - 4 } & & Serpihan & 5 \\
\hline
\end{tabular}

\begin{tabular}{|l|l|c|}
\hline & $\begin{array}{l}\text { Material di } \\
\text { Area Kerja }\end{array}$ & \\
\cline { 2 - 3 } & $\begin{array}{l}\text { Kabel } \\
\text { Pembangkit } \\
\text { Listrik }\end{array}$ & 1 \\
\hline \multicolumn{2}{|c|}{ Total } & $\mathbf{3 4}$ \\
\hline
\end{tabular}

(Sumber : Penambangan PT. Dempo Bangun Mitra)

\section{Penilaian Resiko}

Setelah mendapatkan temuan potensi bahaya di lapangan dan menggolongkan potensi bahaya berdasarkan sumbernya seperti pada tabel 1, maka langkah selanjutnya dilakukan penilaian resiko dengan pendekatan risk matriks.

Hasil observasi lapangan dari 34 temuan potensi bahaya kemudian digolongkan berdasarkan jenis sumbernya menjadi 9 sumber bahaya antara lain : sikap pekerja, kebisingan, lalu lintas tambang, serpihan material, asap, area penyimpanan bahan peledak, debu, serpihan material di area kerja dan kabel pembangkit listrik.

Setelah itu menentukan tingkat keparahan atau perkingan (risk level) dengan mempertimbangkan kriteria resiko Likelihood (L) dengan Severity atau Concequences (C). Dari hasil wawancara yang dilakukan, maka jumlah tingkat bahaya kecelakaan kerja yang diklasifikasikan terhadap nilai Likelihood (L) dengan Concequences (C) sesuai dengan peluang dan resiko tingkat keparahan. Penetapan nilai Likelihood (L) dan Concequences (C) adalah sebagai berikut :

Tabel 2. Penetapan Nilai Likelihood (L) dan Concequences (C)

\begin{tabular}{|c|l|c|c|}
\hline No & \multicolumn{1}{|c|}{$\begin{array}{c}\text { Sumber } \\
\text { Hazard }\end{array}$} & $\begin{array}{c}\text { Likelihood } \\
\text { (L) }\end{array}$ & $\begin{array}{c}\text { Concequences } \\
\text { (C) }\end{array}$ \\
\hline 1 & Sikap Pekerja & 5 & 4 \\
\hline 2 & Kebisingan & 4 & 2 \\
\hline 3 & $\begin{array}{l}\text { lalu lintas } \\
\text { tambang }\end{array}$ & 5 & 5 \\
\hline 4 & $\begin{array}{l}\text { Serpihan } \\
\text { Material }\end{array}$ & 3 & 2 \\
\hline 5 & Asap & 3 & 4 \\
\hline 6 & $\begin{array}{l}\text { Area } \\
\text { penyimpanan } \\
\text { bahan peledak }\end{array}$ & 1 & 2 \\
\hline 8 & Debu & 4 & 3 \\
\hline 7 & $\begin{array}{l}\text { Serpihan } \\
\text { Material di } \\
\text { area kerja }\end{array}$ & 3 & 3 \\
\hline 9 & $\begin{array}{l}\text { Kabel } \\
\text { Pembangkit } \\
\text { Listrik }\end{array}$ & 2 & \multicolumn{2}{|l}{} \\
\hline
\end{tabular}

Setelah penetapan nilai Likelihood (L) dan Concequences (C) maka langkah selanjutnya 
adalah mangalikan nilai Likelihood (L) dan Concequences (C) sehingga hasil perkalian nilai tersebut akan dimasukkan kedalam matris resiko sehingga akan didapatkan peringkat resiko serta mengetahui peringkat yang berniali ekstrim untuk diberika rekomendasi perbaikan, Seperti yang terlihat ada tabel 3.

Tabel 3. Penetapan Matriks Resiko

\begin{tabular}{|c|l|c|c|c|c|c|}
\hline No & \multicolumn{1}{|c|}{$\begin{array}{c}\text { Sumber } \\
\text { Hazard }\end{array}$} & L & C & $\begin{array}{c}\text { L } \\
\mathbf{X} \\
\text { C }\end{array}$ & Warna & $\begin{array}{c}\text { Risk } \\
\text { Level }\end{array}$ \\
\hline 1 & Sikap Pekerja & 5 & 4 & 20 & & Ekstrim \\
\hline 2 & Kebisingan & 4 & 2 & 8 & & Tinggi \\
\hline 3 & $\begin{array}{l}\text { lalu lintas } \\
\text { tambang }\end{array}$ & 4 & 5 & 20 & & Ekstrim \\
\hline 4 & $\begin{array}{l}\text { Serpihan } \\
\text { Material }\end{array}$ & 3 & 2 & 6 & & Sedang \\
\hline 5 & Asap & 3 & 3 & 9 & & Tinggi \\
\hline 6 & $\begin{array}{l}\text { Area } \\
\text { penyimpanan } \\
\text { bahan peledak }\end{array}$ & 1 & 4 & 4 & & Rendah \\
\hline 8 & Debu & 4 & 2 & 8 & & Tinggi \\
\hline 7 & $\begin{array}{l}\text { Serpihan } \\
\text { Material di } \\
\text { area kerja }\end{array}$ & 3 & 3 & 9 & & Tinggi \\
\hline 9 & $\begin{array}{l}\text { Kabel } \\
\text { Pembangkit } \\
\text { Listrik }\end{array}$ & 2 & 3 & 6 & & Sedang \\
\hline
\end{tabular}

Berdasarkan tabel 3, maka dapat dilihat terdapat dua potensi kecelakaan kerja yang bernilai ekstrim yaitu sikap pekerja serta lalu lintas tambang. Maka dari itu kedua potensi kecelakaan kerja tersebut harus diprioritaskan untuk mendapatkan rekomendasi perbaikan.

Terdapat 34 temuan potensi bahaya pada area penambanagan serta pengahan batu andesit di PT. Dempo Bangun Mitra yang kemudian digolongkan menjadi 9 jenis sumber bahaya meliputi: sikap pekerja, kebisingan, lalu lintas tambang, serpihan material, asap, area penyimpanan bahan peledak, debu, serpihan material di area kerja dan kabel pembangkit listrik. Frekuensi temuan terbesar yaitu ditemukannya hazard pada sikap pekerja yang tidak sesuai standar dan prosedur kerja sebanyak 8 temuan, lalu lintas tambang sebesar 6 temuan, debu dan serpihan material di area kerja sebesar 5 temuan, kebisingan sebesar 4 temuan, asap sebesar dan sisanya yaitu area penyimpanan bahan peledak, serpihan material serta kabel pembangkit listrik terdapat sebanyak 1 temuan.

Dari Tabel 4.6 (BAB IV) dapat diketahui terdapat 2 sumber hazard yang memiliki nilai ekstrim, 4 sumber hazard yang memiliki nilai risiko tinggi, 2 sumber hazard yang memiliki nilai risiko sedang, dan 1 sumber hazard yang memiliki nilai risiko rendah. Menurut UNSW Health and Safety (2008) sumber hazard yang memiliki nilai ekstrim harus diprioritaskan untuk mendapatkan rekomendasi atau usulan perbaikan terlebih dahulu. Sumber hazard yang memiliki nilai ekstrim yaitu sikap pekerja serta lalu lintas tambang.

\section{Sumber Hazard "Sikap Pekerja"}

Hasil dari Hazop worksheet dapat menunjukkan bahwa risiko pertama yang memiliki nilai ekstrim yaitu berasal dari sumber hazard sikap pekerja yang tidak memenuhi persyaratan standard dalam keselamatan kerja dan prosedur bekerja yang baik.

Uraian dari sumber hazard "Sikap Pekerja"

adalah sebagai berikut:

1. Sumber hazard dan Frekuensi

Sumber hazard "Sikap Pekerja" ini muncul sebanyak 11 kali selama penelitian ini dilakukan.

2. Deviation (Penyimpangan)

Penyimpangan yang terjadi adalah:

a. Pekerja bertindak tidak aman atau melakukan pekerjaan tidak sesuai dengan SOP.

b. Pekerja tidak menggunakan APD saat melakukan pekerjaan. APD tersebut disesuaikan dengan area kerja masingmasing pekerja. Jenis-jenis APD seperti safety helmet, safety goggles, masker, ear plug, safety gloves, safety shoes, dan safety harness.

3. Cause (Penyebab)

Penyebab dari munculnya penyimpanganpenyimpangan tersebut adalah:

a. Kurang disiplinnya pekerja dalam mengikuti SOP yang ada. Hal ini disebabkan oleh pihak manajemen yang kurang aktif dalam mengontrol dan mengawasi kelangsungan proses kerja.

b. Rendahnya kesadaran dan pengetahuan akan keselamatan kerja yang disebabkan oleh kurang maksimalnya pelaksanaan pelatihan Keselamatan dan Kesehatan Kerja (K3) tentang penggunaan APD. Pelaksanaan pelatihan tersebut sebetulnya sudah terjadwal, hanya saja target peserta pelatihan tersebut kurang maksimal dan peserta yang diundang untuk menghadiri pelatihan tersebut tidak menunjukkan antusiasme untuk menghadiri pelatihan tersebut sehingga peserta pelatihan yang hadir selalu tidak pernah lengkap. Pihak manajemen juga belum melakukan forum diskusi secara rutin untuk membahas dan mengontrol pelaksanaan K3 di perusahaan. Tentu saja hal ini berdampak pada tingginya intensitas kemunculan bahaya yang disebabkan oleh sikap pekerja yang tidak 
memenuhi persyaratan standard dalam keselamatan kerja dan prosedur bekerja yang baik sehingga dapat membahayakan keselamatan dan kesehatan pekerja.

4. Consequences (Konsekuensi)

Konsekuensi yang akan dialami pekerja bila pekerja bertindak tidak aman dan tidak menggunakan APD adalah sebagai berikut:

a. Kepala terbentur

b. Anggota tubuh terluka

c. Terjepit

d. Gangguan pernafasan

e. Gangguan pengelihatan

f. Gangguan pendengaran

g. Terjatuh dari ketinggian

h. Meninggal dunia

Apabila hal ini tidak segera diperbaiki maka akan sangat merugikan perusahaan, khususnya pekerja itu sendiri.

5. Action (Tindakan)

Tindakan yang bisa dilakukan untuk segera mengatasi sumber hazard ini adalah:

a. Membuat visual display untuk mengingatkan pekerja agar selalu menggunakan APD.

b. Membuat prosedur kerja yang baik.

c. Melakukan pelatihan K3 kepada para pekerja secara menyeluruh dan berkesinambungan.

\section{Sumber Hazard "Lalu Lintas Tambang"}

Risiko kedua yaitu berasal dari lalu lintas tambang yang rusak dan berpotensi mengakibatkan kecelakaan lalu lintas pada saat membawa material. Selain itu dengan kondisi lalu lintas yang masih dalam kondisi tanah apabila curah hujan tinggi akan menyebabkan jalan menjadi licin, kendaraan pekerja tergelincir, terjatuh dari ketinggian, dan bahkan bila terperosok ke dalam tebing yang tinggi nyawa pekerja bisa menjadi taruhannya. Berikut ini adalah uraian mengenai sumber hazard "Lalu lintas tambang"

1. Sumber hazard dan Frekuensi

Sumber hazard "Lalu lintas tambang" ini ditemukan sebanyak 6 kali selama penelitian dilakukan.

2. Deviation (Penyimpangan)

Penyimpangan yang terjadi dari sumber hazard ini adalah:

a. Lalu lintas yang masih dari tanah

b. Tidak ada yang membatasi jalan dengan tebing yang tinggi

3. Cause (Penyebab) adalah: a. Kurangnya perawatan yang dilakukan oleh pihak manajemen.

b. Kurangnya rambu-rambu atau tanda yang diberikan oleh pihak manajemen.

4. Consequence (Konsekuensi)

Konsekuensi atau akibat yang akan diterima oleh pekerja yang terkena sumber hazard ini antara lain:

a. Kecelakaan lalu lintas

b. Melukai anggota tubuh

c. Terjatuh dari ketinggian

d. Terperosok ke dalam jurang

5. Action (Tindakan)

Tindakan yang bisa dilakukan untuk segera mengatasi sumber hazard ini yaitu:

a. Segera memperbaiki jalan menjadi lebih baik

b. Melakukan inspeksi kondisi jalan secara rutin.

c. Memberikan rambu-rambu peringatan tentang kondisi jalan yang ada

\section{Kesimpulan}

Adapun kesimpulan pada penelitian ini adalah :

1. Potensi kecelakaan kerja pada proses penambangan adalah

a. Potensi pada sikap pekerja tidak memenuhi persyaratan standard dalam keselamatan kerja dan prosedur bekerja yang baik.

b. Potensi pada lalu lintas tambang yaitutidak adanya rambu - rambu untuk kondisi lalu lintas tambang yang cukup berbahaya.

2. Upaya pengendalian terhadap potensi kecelakaan kerja adalah

a. Melakukan pengawasan terhadap para karyawan serta pelatihan tentang pentingnya APD

b. Memberikan rambu-rambu tentang kondisi jalan serta pengontrolan kondisi jalan secara teratur.

\section{Daftar Pustaka}

Chomiarti, Dian. 2008. Analisis Keselamatan Dan Kesehatan Kerja Berbasis Perilaku Pada Pekerja Konstruksi (Studi Kasus: Pt. Wahana Karsa Swandiri). Tugas Akhir Teknik Industri Fakultas Sains dan Teknologi.

Iskandar, Muhaimin. 2010. Peraturan Menteri Tenaga Kerja dan Transmigrasi Republik Indonesia Nomor PER.08/MEN/VII/2010 tentang Alat 
Pelindung Diri. Jakarta: Kementrian Tenaga Kerja dan Transmigrasi RI.

Yovita, Selvy. 2009. Kesehatan Dan Keselamatan Kerja (K3) Pada Pertambangan Batubara di PT. Marunda Grahamineral, Job Site Laung Tuhup Kalimantan Tengah. Laporan Umum Program Diploma Iii Hiperkes Dan Keselamatan Kerja Fakultas Kedokteran Universitas Sebelas Maret Surakarta.
Pujiono, dkk. 2013. Analisis Potensi Bahaya Serta Rekomendasi Perbaikan Dengan Metode Hazard And Operability Study (HAZOP) Melalui Perangkingan Ohs Risk Assessment And Control. Jurnal Teknik Industri Fakultas Teknik Universitas Brawijaya.

Suma'mur P.K., 1989, Kesehatan Kerja dan Pencegahan Kecelakaan Kerja, Jakarta: CV. Haji Masagung. 